\title{
EFFECT OF DIFFERENT PATTERN CONSTRUCTION TECHNIQUES ON THE MARGINAL ADAPTATION, INTERNAL FIT AND FRACTURE RESISTANCE OF IPS-EMAX PRESS CROWNS
}

\author{
Osama Saleh*, Rania A. Amin* and Mostafa A. Abdellatif**
}

\begin{abstract}
Purpose: The purpose of this study was to evaluate the effect of pattern construction technique on the marginal accuracy, internal fitness and fracture resistance of E-max crowns.

Materials and methods: Thirty caries-free human maxillary first premolars were selected, cleaned by scaling, and stored in $0.9 \%$ standardized saline solution at room temperature. Using an industrial lathe machine, the teeth were prepared to receive all ceramic crowns with standardized dimensions of 6 degrees angle of convergence. The preparation had $5 \mathrm{~mm}$ occluso-cervical height, $6 \mathrm{~mm}$ cervical diameter and $1 \mathrm{~mm}$ deep chamfer finish line. The prepared teeth were divided into three groups $(n=10)$ according to the pattern fabrication techniques used: Group1: Conventional wax patterns. Group2: CAD/CAM wax patterns. Group3: 3D Printing of resin patterns. All patterns were invested to construct E-max crowns. The ceramic crowns were seated on their corresponding prepared teeth and the vertical marginal gap was measured with a binocular microscope (90X). Then internal gap of each ceramic crown was measured using the silicone replica technique. After cementation, each ceramic crown was statically, compressively and axially loaded until fracture at a cross head speed of $1 \mathrm{~mm} / \mathrm{min}$ using a steel rod placed centrally at the occlusal surface of the crowns to evaluate the fracture resistance of the crowns.
\end{abstract}

Results: Group 1 showed the largest marginal gap mean $(85.74 \pm 2.58 \mu \mathrm{m})$ followed by group 2; $(74.06 \pm 3.27 \mu \mathrm{m})$ and then group $3(69.35 \pm 3.44 \mu \mathrm{m})$. These differences were statistically significant among the groups. The results of internal gap distances in group $1(112 \pm 7.66 \mu \mathrm{m})$ followed by group $2(100 \pm 5.76 \mu \mathrm{m})$ and then group3 $(82 \pm 7.2 \mu \mathrm{m})$, the differences between the groups were statistically significant. The mean fracture resistance values of groups 1,2 and 3 were $850.67 \pm 25.30 \mathrm{~N}$, $1080.01 \pm 47.06 \mathrm{~N}$ and $1412.18 \pm 28.92 \mathrm{~N}$ respectively. Post hoc test revealed that the differences between groups 1 and 2 as well as between groups 2 and 3 were statistically insignificant; however, the difference between groups 1 and 3 was statistically significant. Spearman's rank correlation coefficient showed value of -0.781 . The negative sign indicates that the fracture resistance of the samples decreased as the internal gaps increased

Conclusions: The 3D printed pattern resulted in an E-max crown with better marginal adaptation and internal fitness. The fracture resistance of E-max crown was improved as its internal adaptation was enhanced.

* Associate Professor of Crowns and Bridges, Department of Crowns and Bridges, Faculty of Dental Medicine, Al-Azhar University, Girls Branch, Cairo, Egypt

** Lecturer of Dental Materials, Biomaterials Department, Faculty of Oral and Dental Medicine, Future University in Egypt; FUE 


\section{INTRODUCTION}

The interest and demand for metal-free biocompatible restorations from both clinicians and patients has encouraged researchers to seek alternatives. To meet this need, all-ceramic restorations with the advantages of soft tissue biocompatibility, color stability, improved wear resistance, low thermal conductivity, and excellent light transmitting properties have been developed. After aesthetic and mechanical properties, crown marginal adaptation and internal fit are crucial for the clinical success. High marginal adaptation minimizes plaque accumulation, micro-leakage, and cement breakdown. Subsequently, the risk of carious lesions, periodontal disease, and endodontic inflammation are reduced. ${ }^{1}$ The internal fit of the crown is critical for its retention and resistance form; having a better fitness will increase success and longevity. ${ }^{1-7}$ However, an increase in the internal gap could decrease the fracture resistance of ceramic crowns because these areas with a higher internal gap would induce stress concentrations..$^{8-11}$

Crown adaptation is detrmined by the measurements of its marginal and internal gaps. According to Holmes et al; ${ }^{12}$ internal gap is the measurement between the axial wall of the prepared tooth and the internal surface of the crown, while the same measurement at the margin is called marginal gap.

Fabrication of accurate pattern is a key factor that can affect the marginal adaptation and internal fit of heat pressed ceramic crowns. Traditionally, patterns for these restorations have been constructed from inlay casting wax. This technique combines familiarity and ease of manipulation with good reproduction of details and low cost. In the same time, waxes have two main disadvantages; a high coefficient of thermal expansion and tendency for stress relaxation. ${ }^{13}$

By introducing different subtractive as well as additive computer-aided design and computer-aided manufacturing (CAD/CAM) systems, it is possible to fabricate patterns made from materials that can be burned out without any traces as waxes and resins, and omit several limitations of the conventional waxing technique. ${ }^{14}$ Fabrication of patterns from machinable blocks is known as subtractive CAD/ CAM. A more recent technology where a threedimensional component can be built up layer-bylayer using a computerized numerical control (CNC) machine; the additive CAD/CAM approaches also known as $3 \mathrm{D}$ printing technology are beginning to be used in dental CAD/CAM systems. ${ }^{15}$

Using CAD/CAM systems have many advantages such as producing higher and more uniform-quality patterns, standardizing shaping processes and reducing production costs, labor and time. ${ }^{16}$ Another advantage is the potential to enhance accuracy as they omit several fabrication steps during the conventional waxing technique. ${ }^{17}$ Given the simplicity of automatic margin detection and pattern design compared to manual waxing, it makes the most sense to use the CAD/CAM features where possible. ${ }^{18}$

Little data is available about the marginal adaptation and internal fitness afforded by the newer methods of pattern construction in comparison with the conventional method. The aim of this study was to evaluate the effect of different pattern construction techniques on marginal accuracy, internal fitness and fracture resistance of E-max crowns.

\section{MATERIALS AND METHODS}

\section{Samples Preparation}

Thirty caries-free human maxillary first premolars were selected, cleaned by scaling, and stored in $0.9 \%$ standardized saline solution ${ }^{*}$ at room temperature throughout the course of the study to protect them against drying. The teeth were visually examined, and only those that were found to have 
approximately similar dimensions and free from hypoplastic defects and cracks were used. The roots of the teeth were embedded in epoxy resin blocks* up to $2 \mathrm{~mm}$ apical to the cemento-enamel junction.

Using an industrial lathe machine, the teeth were prepared to receive all ceramic crowns with standardized dimensions of 6 degrees angle of convergence. The preparation had $5 \mathrm{~mm}$ occlusocervical height, $6 \mathrm{~mm}$ cervical diameter and $1 \mathrm{~mm}$ deep chamfer finish line. ${ }^{19}$ An occlusal notch was made using a round bur for exact repositioning of the non-anatomic E-max crowns. ${ }^{20}$

\section{Samples Grouping:}

The prepared teeth were divided into three groups $(n=10)$ according to the pattern fabrication techniques used for the construction of heat-pressed lithium-disilicate crowns:

Group1: Conventional wax patterns.

Group2: CAD/CAM wax patterns.

Group3: 3D Printing of resin patterns.

\section{Fabrication of the Patterns:}

\section{Conventional Wax Pattern (Group 1):}

Impression of each prepared tooth was made with polyvinyl siloxane impression material ${ }^{* *}$ using custom made tray and poured into stone die $^{* * *}$. The stone dies were trimmed, and two coats of die spacer $^{* * * *}$ were applied $1 \mathrm{~mm}$ coronal to the finish line with a brush. The bottles were kept closed between applications, and the brush was cleaned frequently with a thinner agent. According to the product manual, each layer of die spacer has a thickness between $12-15 \mu \mathrm{m}$ (approximately equal to $30 \mu \mathrm{m}$ by 2 applications, for standardization between the 3 groups). After drying, a thin layer of separating medium ${ }^{* * * * *}$ was also applied to the walls of the stone dies by the aid of a painting brush.

For the purpose of standardization, a copper counter die was constructed; it provided $1 \mathrm{~mm}$ space for the wax pattern construction. Using inlay casting $\operatorname{wax}^{* * * * * *}$, wax patterns were constructed on the stone dies and then the counter die was applied around the stone die to verify the $1 \mathrm{~mm}$ thickness of the wax pattern. The finished patterns were checked with a magnifying lens (10X) for any marginal or body discrepancy. The cervical margins of the wax were corrected just before investing; a well heated instrument, PKT No. $1^{* * * * * * *}$ was used to melt completely the wax around the preparation margin, then wax was added to fill any deficiencies. When wax has cooled, the excess wax at the margin was carefully trimmed by a carver. The wax pattern was checked for any imperfection and proper adaptation on the finish line.

\section{CAD/CAM Wax Patterns (Group 2):}

The prepared teeth were covered with a thin, opaque layer of powder ${ }^{* * * * * * * *}$ before scanning. Optical impressions of the powdered prepared teeth and the external shape of the finished conventional wax patterns (Group 1) were made by using a noncontact 3D optical scanner ${ }^{* * * * * * * *}$. Based on the scanned files, the patterns were designed by CAD software ${ }^{* * * * * * * * * *}$ with cement gap set to be $30 \mu \mathrm{m}$ started $1 \mathrm{~mm}$ coronal to the finish line.

\footnotetext{
* Kemapoxy 150, solvent free transparent epoxy resin, CMB International, Egypt

** Imprint II, 3M, ESPE, Minnesota USA

*** Degussa, AG, Frankfurt, Germany

**** PICO-FIT red; Renfert GmbH, Hilzingen, Germany

***** Picosep; Renfert GmbH, Hilzingen, Germany

****** Renfert casting wax, Renfert GmbH, Hilzingen, Germany

******* PKT waxing 1; Dental USA Inc, McHenry, USA

********* Okklu-Exact, Germany

********** Identica Blue, Medit Co., LTD, Seoul, Korea

$* * * * * * * * * *$ Exocad software
} 
A 5-axis milling unit * was used for CAM processing of the designed patterns from wax discs**.

\section{D Printing of Resin Patterns (Group 3):}

For the purpose of standardization, the 3D CAD data (Group 2) was reformatted in order to be used for software specific for $3 \mathrm{D}$ printing; STereoLithography (STL) file format. The patterns were produced using a $3 \mathrm{D}$ printer ${ }^{* * *}$, this printer utilizes the art of Direct Light Projection (DLP®) from Texas instruments ${ }^{\circledR}$ to cure the wax-filled photopolymer resin material $^{* * * *}$.

\section{Fabrication of Monolithic IPS e.max Press Crowns}

All patterns were invested with a special type of phosphate-bonded investment material ${ }^{* * * * *}$. After the burn-out of the pattern in the conventional preheating furnace, ceramic ingot ${ }^{* * * * * *}$ was plastified at $920^{\circ} \mathrm{C}$ and pressed under vacuum into the investment mold in the furnace ${ }^{* * * * * * *}$. All crowns were checked for the macroscopic fit on their corresponding prepared teeth. Crowns that had deficiencies at the margins were not included in the study. The intaglio surfaces of the crowns were then checked for fit with an aerosol indicator-marking spray ${ }^{* * * * * * * *}$. Any discontinuity of the spray that indicated fitting surface interferences was eliminated with a small diamond bur $^{* * * * * * * * *}$ under copious water irrigation. Finally, the crowns were ultrasonically ${ }^{(10)}$ cleaned in a distilled water bath for five minutes, and then dried in air.

\section{Testing Procedures}

\section{Vertical Marginal Fit Assessment}

The ceramic crowns were seated on their corresponding prepared teeth and the vertical marginal gap distance between the outer cervical margin of each crown and the finish line of the prepared tooth was measured. A specially designed holding device was used to fix and ensure the seating accuracy of the tested crowns on their corresponding teeth during the examination with a binocular microscope $\mathrm{e}^{* * * * * * * * * *}$ (90X). Digital images of the margins were captured at the cervical circumference of the 4 aspects of each crown; buccal, lingual, mesial, and distal aspect. These images were then analyzed with image analysis software $^{* * * * * * * * * * *}$. Five measurements were made at each of the four points, for a total of 20 measurements per crown. The mean of the 20 values represented the mean vertical marginal gap for each crown.

\section{Internal Fit Assessment}

The internal fit was assessed by measuring the internal gap distance. The internal gap of each ceramic crown was measured using the silicone replica technique. A light-body silicone rubber impression material ${ }^{* * * * * * * * * * * * * * *}$ was used. Each crown

\footnotetext{
* Vhf-S1, Germany

** Copra wax, White Peaks, Germany

*** Perfractory Desktop Digital Dental Printer (DDDP, EnvisionTEC, Germany

**** Press-E-cast, EnvisionTEC, Germany

***** IPS-Press VEST Speed; Ivoclar Vivadent

$* * * * * *$ IPS e.max Press; Ivoclar Vivadent

******** EP 600; Ivoclar Vivadent

******** Okklufine Premium; FINO GmbH, Bad Bocklet, Germany

********* Mani Dia-Burs; Mani Inc, Tochigi-Ken, Japan

*********** Vitasonic, VitaZahnfabrik, Bad Sackingen Germany

*********** SZ-PT; Olympus, Tokyo, Japan

************* Optimas 6.5; Media Cybernetics, Rockville, Md

************** Aquasil LV, green color, Dentsply, Germany
} 
was filled with the light-body material and placed on the corresponding prepared tooth with a constant load of $5 \mathrm{~kg}$ for 3 minutes using a universal testing machine*.

After setting of the silicone rubber, the crowns were removed from the teeth. The film of the impression material adherent to the inner surface of the crown represents the internal gap. To support this thin silicone film, a heavy-body material with a contrasting color** was placed in the crown to form one piece with the light body film. After setting of the supporting heavy-body material, each silicone replica was removed from the crown and carefully segmented with a sharp surgical blade bucco-lingually and mesio-distally into four pieces. The thickness of the light body silicone replica was measured using the binocular microscope (90X). Measurements were taken at 4 different points; $1 \mathrm{~mm}$ occlusal to the finish line, mid - axial,

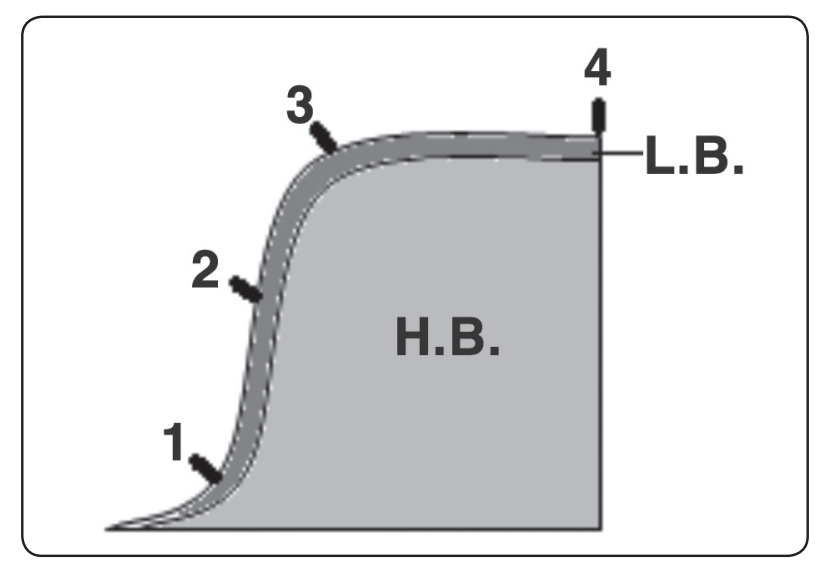

Fig. (1) Diagram representing the silicone replica (light body; L.B. and heavy body; H.B.). The four measurment points for the internal fit acessment: $1 \mathrm{~mm}$ occlusal to the finish line, mid - axial, occluso - axial and mid - occlusal are represented by points 1,2, 3 and 4 respectively.

\footnotetext{
* Model 3345; Instron Instruments Ltd, USA

** Aquasil Putty, blue color, Dentsply, Germany

*** Ivoclar, Vivadent, Schaan, Liechtenstein

**** Monobond-S, Vivadent, Schaan, Liechtenstein

******3M ESPE, Seefeld, Germany

$* * * * * *$ Bluehill Lite; Instron Instruments Ltd
}

occluso - axial and mid - occlusal, Figure 1. The mean thickness of those four measurements on all quadrants of each specimen was considered as the mean internal gap width. All measuring procedures were performed by the same operator.

\section{Cementation of the ceramic crowns:}

After removal of the silicone film, each ceramic crown was ultrasonically cleaned and its fitting surface was etched for 2 minutes with hydrofluoric $\operatorname{acid}^{* * *}$, then silane treated ${ }^{* * * *}$ according to the manufacturer's recommendations.

The ceramic crowns were cemented onto their corresponding prepared teeth using RelyX Unicem resin cement ${ }^{* * * * *}$; the cementation process followed the manufacturer's instructions.

Ceramic crowns were initially seated on the prepared teeth with finger pressure then a static load of $5 \mathrm{~kg}$ was applied for 5 minutes using the universal testing machine. Then the ceramic crown-tooth assemblies were stored in distilled water for 24 hours at room temperature.

\section{Fracture Resistance Test:}

Each assembly of the ceramic crown cemented to its corresponding tooth was vertically mounted in the lower fixed grip of the computer operated universal testing machine. Each ceramic crown was statically, compressively and axially loaded until fracture at a cross head speed of $1 \mathrm{~mm} / \mathrm{min}$ using a steel rod placed centrally at the occlusal surface of the crowns, Figure 2. For each assembly, the failure manifested by audible crack and confirmed by sudden drop in the load-deflection curve was recorded in Newton by the machine software $^{* * * * * *}$. 


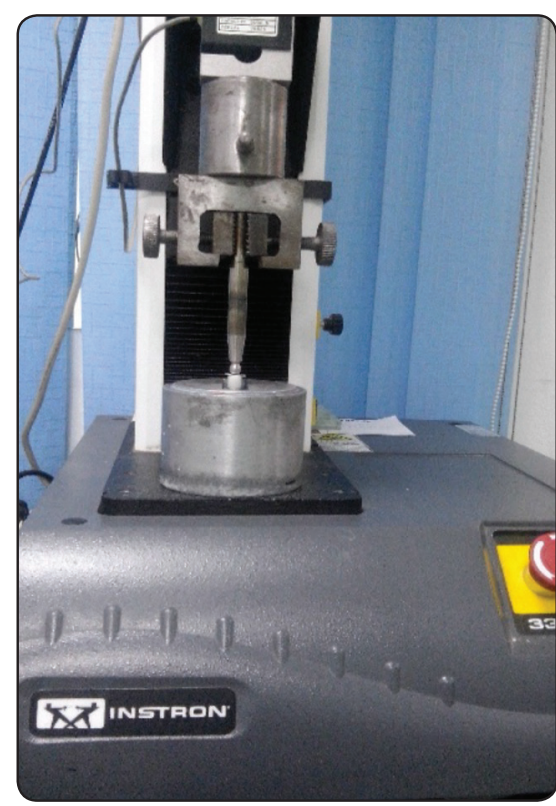

Fig. (2) Fracture resistance of cemented samples evaluated using Instron testing machine.

\section{Statistical analysis}

The obtained results were checked for normality of distribution. Normally distributed values were summarized as mean and standard deviation (SD) and compared by Analysis of Variance (ANOVA) test at level of significance $\mathrm{p}=0.01$. Significantly different results were investigated to detect which technique resulted in this difference using the Tukey's Post Hoc multiple comparisons for observed means test at level of significance $\mathrm{p} \leq 0.01$. Sperman's test was used for assessment of the correlation between the internal gap distance of each cemented crown and its corresponding fracture resistance. All statistical analyses were performed using SPSS 20.0 for Windows.

\section{RESULTS}

\section{Vertical marginal fit and internal fit}

Values of marginal vertical gap distances can be demonstrated in Figure 3. Table 1 and Figure 4 and Figure 5 show the means and standard deviations of vertical marginal gaps as well as internal gaps respectively in each group. The vertical marginal gap of group 1; E-max crown constructed using conventional wax pattern showed the largest marginal gap mean $(85.74 \pm 2.58 \mu \mathrm{m})$ followed by group 2 ; CAD/CAM wax pattern $(74.06 \pm 3.27 \mu \mathrm{m})$ and then group3; 3D printing of resin patterns $(69.35 \pm 3.44 \mu \mathrm{m})$. These differences were statistically significant among the groups.

The results of internal gap distances followed the same pattern as the highest mean values for the internal gap were found in group 1 $(112 \pm 7.66 \mu \mathrm{m})$ followed by group $2(100 \pm 5.76 \mu \mathrm{m})$ and then group3 $(82 \pm 7.2 \mu \mathrm{m})$. Once again, the differences between the groups were statistically significant.

TABLE (1) Means and standard Deviation of vertical marginal gap and internal gap distance in $\mu \mathrm{m}$

\begin{tabular}{|l|c|c|c|c|c|c|c|}
\hline & \multicolumn{2}{|c|}{ Group 1 } & \multicolumn{2}{c|}{ Group 2 } & \multicolumn{2}{c|}{ Group 3 } & $\begin{array}{c}\text { One Way } \\
\text { ANOVA }\end{array}$ \\
\cline { 2 - 8 } & Mean & SD & Mean & SD & Mean & SD & P-value \\
\hline $\begin{array}{l}\text { Vertical marginal } \\
\text { gap distances }\end{array}$ & $85.74^{\mathrm{a}}$ & 2.58 & $74.06^{\mathrm{b}}$ & 3.27 & $69.35^{\mathrm{c}}$ & 3.44 & 0.000 \\
\hline $\begin{array}{l}\text { Internal gap } \\
\text { distances }\end{array}$ & $112.00^{\mathrm{a}}$ & 7.66 & $100.00^{\mathrm{b}}$ & 5.76 & $82.00^{\mathrm{c}}$ & 7.20 & 0.000 \\
\hline
\end{tabular}

In each row, values sharing the same letters are statistically insignificant. 


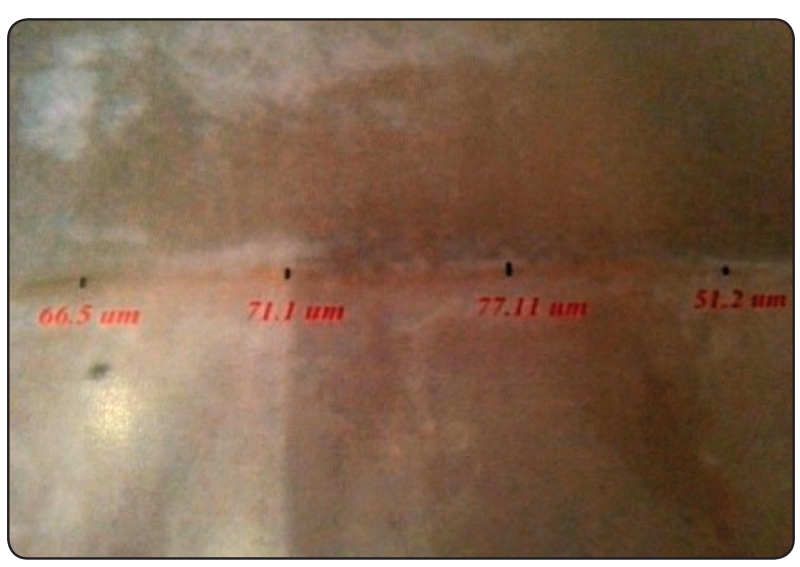

Fig. (3) Vertical marginal gap evaluation using a binocular microscope in $\mu \mathrm{m}$

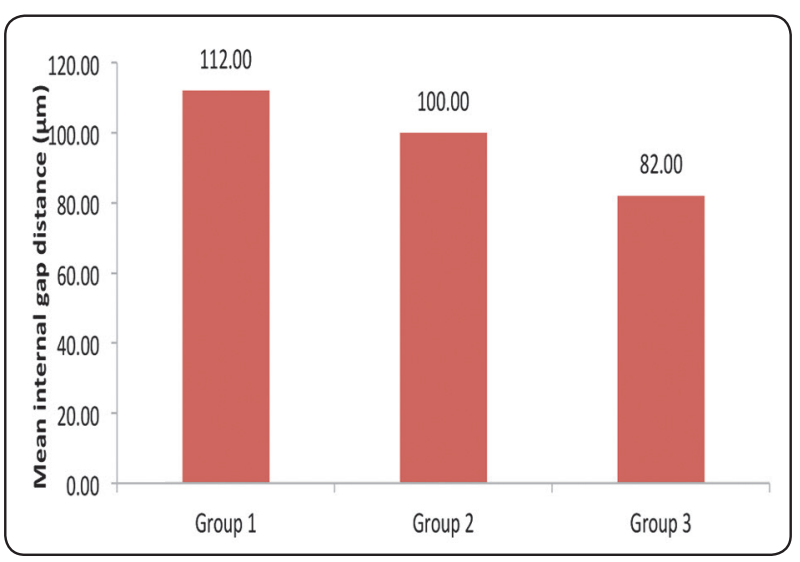

Fig. (5) Mean internal gap distance values in $\mu \mathrm{m}$

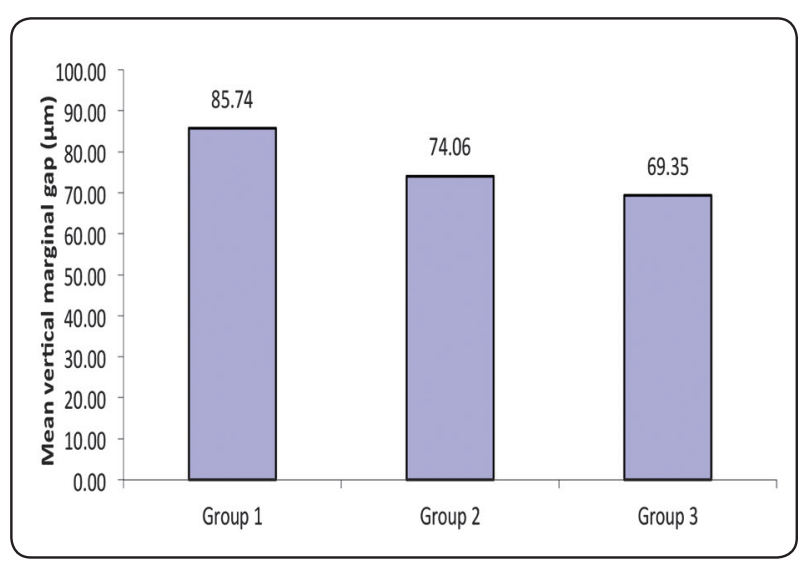

Fig. (4) Mean vertical marginal gap values in $\mu \mathrm{m}$

\section{Fracture resistance}

Table 2 and Figure 6 show the means and standard deviations of fracture resistance in each group in Newton. The mean fracture resistance values of groups 1,2 and 3 were $850.67 \pm 25.30 \mathrm{~N}$, $1080.01 \pm 47.06 \mathrm{~N}$ and $1412.18 \pm 28.92 \mathrm{~N}$ respectively. Post hoc test revealed that the differences between groups 1 and 2 as well as between groups 2 and 3 were statistically insignificant; however, the difference between groups 1 and 3 was statistically significant.

TABLE (2) Means and standard Deviation of fracture resistance in Newton

\begin{tabular}{|l|c|c|c|c|c|c|c|}
\hline \multirow{2}{*}{} & \multicolumn{2}{|c|}{ Group 1 } & \multicolumn{2}{c|}{ Group 2 } & \multicolumn{2}{c|}{ Group 3 } & $\begin{array}{c}\text { One Way } \\
\text { ANOVA }\end{array}$ \\
\cline { 2 - 8 } & Mean & SD & Mean & SD & Mean & SD & P-value \\
\hline Fracture resistance & $850.67^{\mathrm{a}}$ & 25.30 & $1080.01^{\mathrm{ab}}$ & 47.06 & $1412.18^{\mathrm{b}}$ & 28.92 & 0.000 \\
\hline
\end{tabular}

Values sharing the same letters are statistically insignificant. 


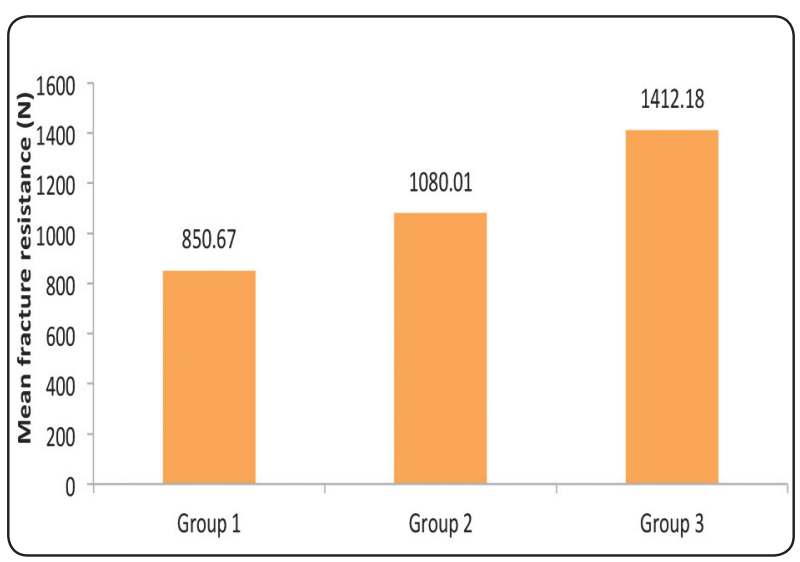

Fig. (6) Mean fracture resistance (load) values in Newton

\section{Correlation between internal fit and fracture resistance}

Spearman's rank correlation coefficient showed value of - 0.781. The negative sign indicates that the fracture resistance of the samples decreased as the internal gaps increased, Table 3 and Figure 7

TABLE (3) Results of Spearman's rank correlation coefficient

\begin{tabular}{|l|c|c|}
\hline \multirow{2}{*}{} & \multicolumn{2}{|c|}{ Internal fit } \\
\cline { 2 - 3 } & $\mathbf{R}$ & p-value \\
\hline Fracture resistance & -0.781 & 0.000 \\
\hline
\end{tabular}

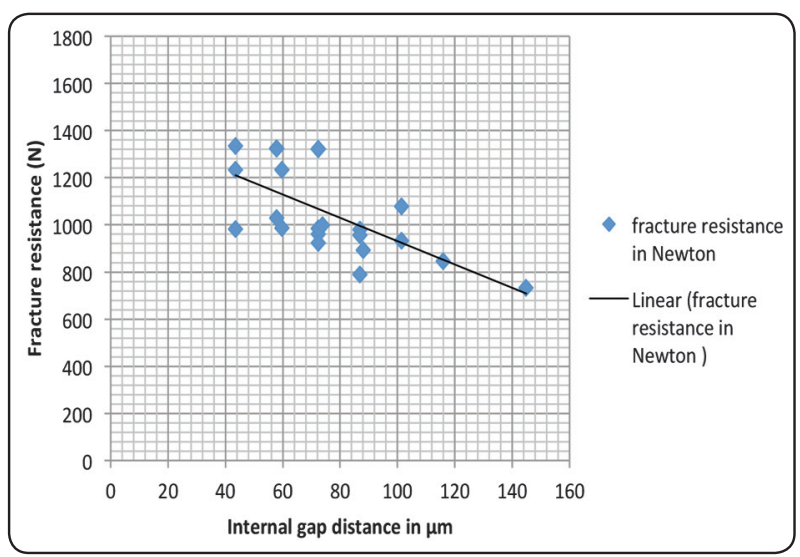

Fig. (7) Correlation between internal gap distance in $\mu \mathrm{m}$ and fracture resistance in Newton

\section{DISCUSSION}

Fabrication of an accurate pattern is a crucial step that can affect the marginal and internal adaptation of all-ceramic restorations. Pattern formation employs materials like inlay casting wax, auto- polymerizing and light cured resins. Distortion of wax pattern like shrinkage due to relaxation of internal stresses contributes to detrimental effects on the final restoration. ${ }^{21-23}$ Resins were recommended as pattern forming materials to overcome the shortcomings of wax. They offer strength, rigidity, and dimensional stability if immediate investment is not possible. However, the disadvantage of these materials is its polymerization shrinkage. Hence, newer light polymerized dimethacrylate modeling resins were used which can be manipulated with increased precision and stability after light polymerization. ${ }^{24-26}$

$\mathrm{CAD} / \mathrm{CAM}$ pattern construction technique is carried out using either polymethyl methacrylate (PMMA) or wax blocks. The CAD/CAM system is a type of subtractive manufacturing that cuts the materials to the desired shape and size. This technique of pattern construction has the advantage of elimination of human variability and time saving. Furthermore, five-axis milling technology that was used in the current study is said to improve productivity and precision by using the machine's additional axes; the 2 additional orientation axes allow the machining of more accurate complex patterns, which cannot be machined with 3 -axis machines. Also, it has superior cutting conditions and improves the efficiency of the milling process by creating efficient tool paths which improve the dimensional accuracy, surface texture, and surface finish of the milled products..$^{27,28}$

However, there are three main factors that could affect the fit of restorations fabricated by these systems: the precision of the scanner that reads the abutments, how the software can transform the scanning data into a $3 \mathrm{D}$ model in the computer and the precision of the milling machine that will 
CAM the objects from the CAD data. ${ }^{29-32}$ Bornemann et al; ${ }^{33}$ stated that "these systems tend to reduce accuracy through the different steps of scanning process, software design, milling, and other related processes". Moreover, these systems result in too much consumption of raw material and cutting tools. Accordingly, the additive manufacturing as $3 \mathrm{D}$ printing method, has been introduced as an appropriate technology-intensive alternative in this field. ${ }^{33}$

Among the various studies, different methods were used to measure vertical marginal gap distances as direct microscopic examination of the marginal area, microscopic examination of cross sectioned cemented specimens, measurement of light body silicone replica, $x$-ray microtomography, profilometry and laser videography. ${ }^{34}$ In this study, marginal adaptation was evaluated using direct microscopic examination which is a simple and convenient method, while internal fitness was measured using light body silicone replica. Replica technique is a reliable and accurate method for evaluation of accuracy of dental restorations, which also allows quantification of discrepancies on the inner surfaces and marginal edge of the crown..$^{34}$

In the literature there is no agreement concerning the number of measure sites necessary to evaluate the marginal fit. Yet, this parameter seems critical because within a distance of $300 \mu \mathrm{m}$, the marginal opening can fluctuate by $100 \mu \mathrm{m}$ on the same specimen..$^{35}$ Groten et al; ${ }^{36}$ suggested taking 50 measurements for the marginal fit to limit the numerical variance to $\pm 5 \mu \mathrm{m}$. In 2004, Gassino et $\mathrm{al} ;{ }^{37}$ argued that the results of Groten et al; ${ }^{36}$ were erroneous and concluded that at least 18 observation points were necessary to evaluate experimental crowns. In the current study, 20 readings were measured for each crown.

Many studies attempted to determine whether measurements made on the die differed from those made on the abutment tooth. ${ }^{38-44}$ Only some of these studies noted a significant discrepancy among the values of marginal fit measured on the die and on the tooth. ${ }^{38,42}$ Measurements in this study were performed on the prepared teeth to assure better simulation to the real clinical conditions.

Measurements in this study were conducted before cementation, as measurements after cementation do not allow for either the determination of a system's intrinsic precision or the relative impact of the cementation process on the marginal fit. ${ }^{36}$

An occlusal groove (notch) was prepared on the teeth. This groove acts as both, a guide to ensure that the crown was placed in the exact position as well as an anti rotational mean. Similar technique was described by Quintas et al; ${ }^{20}$ and Farid et al. ${ }^{45}$

The reason for comparatively high marginal gap and low internal fitness; Table 1, Figure 4 and Figure 5 for group 1 may be due to human, materials and technical variability as impression process, shrinkage during cooling of the wax pattern, and stress relaxation. In contrast, in group 2 with subtractive CAD/ CAM wax pattern construction technique, materials and technical variability were eliminated and thermal changes as well. However, this method showed some inaccuracies due to the limitation of finite resolution, which can result in edges that are slightly rounded. The point clouds obtained in scanning are transformed through a CAD software algorithm into a smooth and continuous surface, which can also lead to some internal inaccuracies. This can lead to interfering contacts at the incisal/occlusal edges and can be detrimental if they occur at the margins. ${ }^{18}$ Moreover, a large marginal gap could result from an internal cutting bur larger than the desired fine details in the milled pattern. ${ }^{46,47}$

The enhanced adaptation of group 3 for 3D printed pattern (both at the margin and internally) may be due to enhanced precision without any chance of manual errors during fabrication process. 
The results of marginal and internal gaps for all the groups presented in this study can be considered clinically acceptable. Studies considered the marginal gap values of 100 to $200 \mu \mathrm{m}$ to be clinically acceptable for cemented restorations. ${ }^{2,44,48-51}$ More recent studies have considered the clinically acceptable marginal gap values to be less than $100 \mu \mathrm{m} .^{7,8,44,52}$ On the other hand many studies considered the ideal internal gap distance to be between 50 and $100 \mu \mathrm{m}$ and this could result in the most favorable resin cement performance. An internal gap distance of 200 to $300 \mu \mathrm{m}$ also may be clinically acceptable, but this requires in vivo confirmation. ${ }^{53-55}$

In this study, a thicker internal gap distance in groups 1 and 2 had adverse impact on the fracture resistance of E-max crowns, as higher strength was recorded in the group with lower cement space; group 3; Table 3 and Figure 7. This result of the current study is in agreement with Tuntiprawon and Wilson ${ }^{56}$ who reported that all-ceramic crowns exhibited greater fracture strength with $73 \mu \mathrm{m}$ cement thickness at the axial wall. When cement thickness was increased to $122 \mu \mathrm{m}$, lower fracture strength was obtained. They attributed it to the fact that ceramic materials have inherent brittle nature so that as low deflection as 0.1 to $0.2 \%$ would result in complete displacement of atomic plains from their equilibrium positions. Hence, the increase in the luting cements thickness would result in greater deformation of ceramic crowns and therefore less force was needed to fracture the ceramic crowns. Furthermore, poorly fitting indirect ceramic restorations are supported mainly by the luting cement rather than the tooth substance, which might influence the longevity of the restorations. ${ }^{57}$ Moreover, viscoelastic deformation of a thick cement layer may cause residual stresses on the tensile surface of a ceramic crown under loading, this increased tensile stresses may initiate fracture of this crown. ${ }^{58}$

\section{CONCLUSIONS}

1. The 3D printed pattern resulted in an E-max crowns with better marginal adaptation and internal fitness.

2. Fracture resistance of E-max crown was improved as their internal adaptation were enhanced.

\section{REFERENCES}

1. Sailer I, Fehér A, Filser F, Gauckler LJ, Lüthy H and Hämmerle $\mathrm{CH}$ : Five-year clinical results of zirconia frameworks for posterior fixed partial dentures. Int J Prosthodont 2007; 20:383-388.

2. Cruz MA, Sorenson JA and Johnson WK: Effect of venting and seating techniques on the cementation of complete coverage restorations. Oper Dent 2008; 33: 690-695.

3. Luthardt RG, Bornemann G, Lemelson S, Walter MH, Huls A. An innovative method for evaluation of the 3-D internal fit of CAD/CAM crowns fabricated after direct optical versus indirect laser scan digitizing. Int J Prosthodont 2004;17:680-5.

4. Karlsson S. The fit of Procera titanium crowns. An in vitro and clinical study. Acta Odontol Scand 1993;51:129-34.

5. Oden A, Andersson M, Krystek-Ondracek I, Magnusson D. Five-year clinical evaluation of Procera AllCeram crowns. J Prosthet Dent 1998;80:450-6.

6. Besimo C, Jeger C, Guggenheim R. Marginal adaptation of titanium frameworks produced by CAD/CAM techniques. Int J Prosthodont 1997;10:541-6.

7. May KB, Russell MM, Razzoog ME, Lang BR. Precision of fit: the Procera AllCeram crown. J Prosthet Dent 1998;80:394-404.

8. Souza RO, Ozcan M, Pavanelli CA, Buso L, Lombardo GH, Michida SM, et al. Marginal and internal discrepancies related to margin design of ceramic crowns fabricated by a CAD/CAM system. J Prosthodont 2012; 21:94-100.

9. Nakamura T, Dei N, Kojima T, Wakabayashi K. Marginal and internal fit of Cerec $3 \mathrm{CAD} / \mathrm{CAM}$ all ceramic crowns. Int J Prosthodont 2003; 16:244-8.

10. Wiskott HW, Belser UC, Scherrer SS. The effect of film thickness and surface texture on the resistance of cemented extracoronal restorations to lateral fatigue loading. Int $\mathrm{J}$ Prosthodont 1999;12:255-62. 
11. Lang NP, Kiel RA, Anderhalden K. Clinical and microbiological effects of subgingival restorations with overhanging or clinically perfect margins. J Clin Periodontol 1983;10:563-78.

12. Holmes JR, Bayne SC, Holland GA, Sulik WD. Considerations in measurement of marginal fit. J Prosthet Dent 1989;62:405-8.

13. Rajagopal P, Chitre V, Aras MA, A comparison of the accuracy of patterns processed from an inlay casting wax, an autopolymerized resin and a light- cured resin pattern material. Indian J Dent Res 2012; 23:152-156.

14. Cehreli M, Kökat A, Akga K. CAD/CAM zirconia vs. slipcast glass infiltrated alumina/zirconia all ceramic crowns: 2-year results of randomized controlled clinical trial. J Appl Oral Sci. 2009;17(1):49-55.

15. Silva NR, Witek L, Coelho PG, Thompson VP, Rekow ED and Smay J: Additive CAD/CAM process for dental prostheses. J Prosthodont 2011; 20(2): 93-96.

16. Etman MK, Woolford M, Dunne S. Quantitative measurement of tooth and ceramic wear: in vivo study. Int J Prosthodont. 2008;21:245-52.

17. Buso L, Hilgert E, Neisser MP, Bottino MA. Marginal fit of electroformed copings before and after the coction of the porcelain. Braz J Oral Sci. 2004;3(8):409-13.

18. Gonzalo E, Suärez MJ, Serrano B, Lozano JF. A comparison of the marginal discrepancies ofzirconium and metal ceramicfixed dental prostheses before and after cementation. J Prosthet Dent. 2009;102:378-84.

19. Attia A, Kern M. Influence of cyclic loading and luting agents on the fracture load of two all ceramic crown systems. J Prosthet Dent 2004; 92:551-6.

20. Quintas AF, Oliveria F, Bottino MA, Vertical marginal discrepancy of ceramic copings with different ceramic materials, finish lines and luting agents: an in vitro evaluation. $\mathrm{J}$ Prosth Dent 2004; 92:250-257.

21. Ushiwata O, de Moraes JV Method for marginal measurements of restorations: accessory device for toolmarks microscope. J Prosthet Dent 2000; 83:362-366.

22. Blackman R, Baez R, Barghi N Marginal accuracy and geometry of cast titanium copings. J Prosthet Dent1992; $67: 435-440$.

23. Marsaw FA, de Rijk WG, Hesby RA, Hinman RW, Pelleu GB Jr Internal volumetric expansion of casting investments. J Prosthet Dent 1984;52(3):361-366.
24. Milan FM, Consani S, Sobrinho CL, Sinhoreti MA, Sousa-Neto MD, Knowles JC Influence of casting methods on marginal and internal discrepancies of complete cast crowns. Braz Dent J 2004; 15:127-132.

25. Ogura H, Raptis CN, Asgar K (1981) Inner surface roughness of complete cast crowns made by centrifugal casting machines. J Prosthet Dent 45(5):529-535

26. White SN, Zhaokun Y, Tom JF, Sanngsurasak S (1995) In vivo marginal adaptation of cast crowns luted with different cements. J Prosthet Dent 74(1):25-32.

27. Hamza TA, Ezzat HA, El-Hossary MM, Katamish HA, Shokry TE and Rosenstiel SF: Accuracy of ceramic restorations made with two CAD/CAM systems. J Prosthet Dent 2013; 109: 83-87.

28. Song T, Kwon T, Yang J, Han J, Lee J, Kim S and Yeo I: Marginal fit of anterior 3-unit fixed partial zirconia restorations using different CAD/CAM systems. J Adv Prosthodont 2013; 5:219-225.

29. Persson A, Andersson M, Oden A and Sandborgh-Englund G: A three-dimensional evaluation of a laser scanner and a touch-probe scanner. J Prosthet Dent 2006; 95:194-200.

30. Beuer F, Schweiger J and Edelhoff D: Digital dentistry: an overview of recent developments for CAD/CAM generated restorations. Br Dent J 2008; 204:505-511.

31. Örtorp A, Jönsson D, Mouhsen A and von Steyern PV: The fit of cobalt-chromium three-unit fixed dental prostheses fabricated with four different techniques: a comparative in vitro study. Dent Mater 2011; 27: 356-363.

32. Renne W, McGill ST, Forshee KV, DeFee MR and Mennito AS: Predicting marginal fit of CAD/CAM crowns based on the presence or absence of common preparation errors. J Prosthet Dent 2012; 108:310-315.

33. Bornemann G, Lemelson S, Luthardt R. Innovative method for the analysis of the internal 3D fitting accuracy of Cerec-3crowns. Int J Comput Dent 2002;5:177-82

34. Park J Y, Young Kim H Y, Kim H, Jae-Hong KimJ H, Kim W C. Comparison of prosthetic models produced by traditional and additive manufacturing methods J Adv Prosthodont 2015;7:294-302

35. Trifkovic, B. Budak, I. A. Todorovic, A. Hodolic, J. Puskar3, A. Jevremovic, D. and D. Vukelic, D. Application of Replica Technique and SEM in Accuracy Measurement of Ceramic Crowns. Measurement Science Review, Volume 12, No. 3, 2012: 90-97 
36. Groten M, Axmann D, Probster L, Weber H. Determination of the minimum number of marginal gap measurements required for practical in-vitro testing. J Prosthet Dent 2000;83:40-9.

37. Gassino G, Barone Monfrin S, Scanu M, Spina G, Preti G. Marginal adaptation of fixed prosthodontics: a new in vitro 360-degree external examination procedure. Int J Prosthodont 2004;17: 218-23.

38. Pera P, Gilodi S, Bassi F, Carossa S. In vitro marginal adaptation of alumina porcelain ceramic crowns. J Prosthet Dent 1994;72: 585-90.

39. Coli P, Karlsson S. Fit of a new pressuresintered zirconium dioxide coping. Int J Prosthodont 2004;17:59-64.

40. Naert I, Van der Donck A, Beckers L. Precision of fit and clinical evaluation of all-ceramic full restorations followed between 0.5 and 5 years. J Oral Rehabil 2005;32:51-7.

41. Al-Rabab'ah MA, Macfarlane TV, McCord JF. Vertical marginal and internal adaptation of all-ceramic copings made by CAD/CAM technology. Eur J Prosthodont Restor Dent 2008;16:109-15.

42. D’Arcy BL, Omer OE, Byrne DA, Quinn F. The reproducibility and accuracy of internal fit of Cerec 3D CAD/ CAM all ceramic crowns. Eur J Prosthodont Restor Dent 2009; 17:73-7.

43. Comlekoglu M, Dundar M, Ozcan M, Gungor M, Gokce B, Artunc C. Influence of cervical finish line type on the marginal adaptation of zirconia ceramic crowns. Oper Dent 2009;34:586-92.

44. Lee KB, Park C, Kim K and Kwon T, Marginal and Internal Fit of All-ceramic Crowns Fabricated with Two Different CAD/CAM Systems. DMJ 2008; 27(3): 422-426

45. Farid F, Hajimiragha H, Jelodar R, Mostafavi AS, Nokhbatolfoghahaie H. In Vitro evaluation of the effect of core thickness and fabrication stages on the marginal accuracy of an all-ceramic system. J Dent 2012;9:188-194.

46. Lee KB, Park CW, Kim KH and kwon TY: Marginal and internal fit of all-ceramic crowns fabricated with two different CAD/CAM systems. Dent Mater 2008; 27: 422-426.
47. Abduo J, Lyons K and Swain M: Fit of zirconia fixed partial denture: a systematic review. J Oral Rehabil 2010; 37:866-876.

48. Renne W, McGill ST, Forshee KV, DeeFee MR, Mennito AS. Predicting marginal fit of CAD/CAM crowns based on the presence or absence of common preparation errors. J Prosthet Dent 2012; 108:310-5.

49. Boening KW, Wolf BH, Schmidt AE, Kastner K, Walter MH. Clinical fit of Procera AllCeram crowns. J Prosthet Dent 2000; 84:419-24.

50. McLean JW, von Fraunhofer JA. The estimation of cement film thickness by an in vivo technique. Br Dent $\mathrm{J}$ 1971;131:107-11.

51. Yeo IS, Yang JH, Lee JB. In vitro marginal fit of three allceramic crown systems. J Prosthet Dent 2003;90:459-64.

52. Pelekanos S, Koumanou M, Koutayas SO, Zinelis S, Eliades G. Micro-CT evaluation of the marginal fit of different In-Ceram alumina copings. Eur J Esthet Dent 2009; 4:278-92.

53. Mormann WH, Bindl A, Luthy H, Rathke A. Effects of preparation and luting system on all-ceramic computergenerated crowns. Int J Prosthodont 1998;11:333-9

54. Mou SH, Chai T, Wang JS, Shiau YY. Influence of different convergence angles and tooth preparation heights on the internal adaptation of Cerec crowns. J Prosthet Dent 2002;87:248-55

55. Molin MK, Karlsson SL, Kristiansen MS. Influence of film thickness on joint bend strength of a ceramic/resin composite joint. Dent Mater 1996;12:245-9.

56. Tuntiprawon M, Wilson PR. The effect of cement thickness on the fracture strength of all-ceramic crowns. Aust Dent J 1995; 40: 17-21.

57. Mansur Varjão F, Cláudio J, Segalla M, Beloti AM, Elena L, Andrade H De. Study On Film Thickness Of Four Resin Cements. Rev Odontol UNESP. 2002; 31(2):171-7.

58. Rekow D, Thompson VP. Near-surface damage: a persistent problem in crowns obtained by computer-aided design and manufacturing. Proc Inst Eng H 2005; 219: 233-243. 